\title{
Biomolecular Science
}

The research goal of NREL's Biomolecular Science is to enable cost-competitive advanced lignocellulosic biofuels production by understanding the science critical for overcoming biomass recalcitrance and developing new product and product intermediate pathways.

\section{Capabilities}

\section{Biomass Structure}

- Biomass pretreatment chemistry

- High through-put biomass digestibility screening

- Nanoscale biomass structural characterization.

\section{Enzymes}

- Fungal molecular biology

- Enzyme engineering, purification, and assays

- Macromolecular dynamics and simulation.

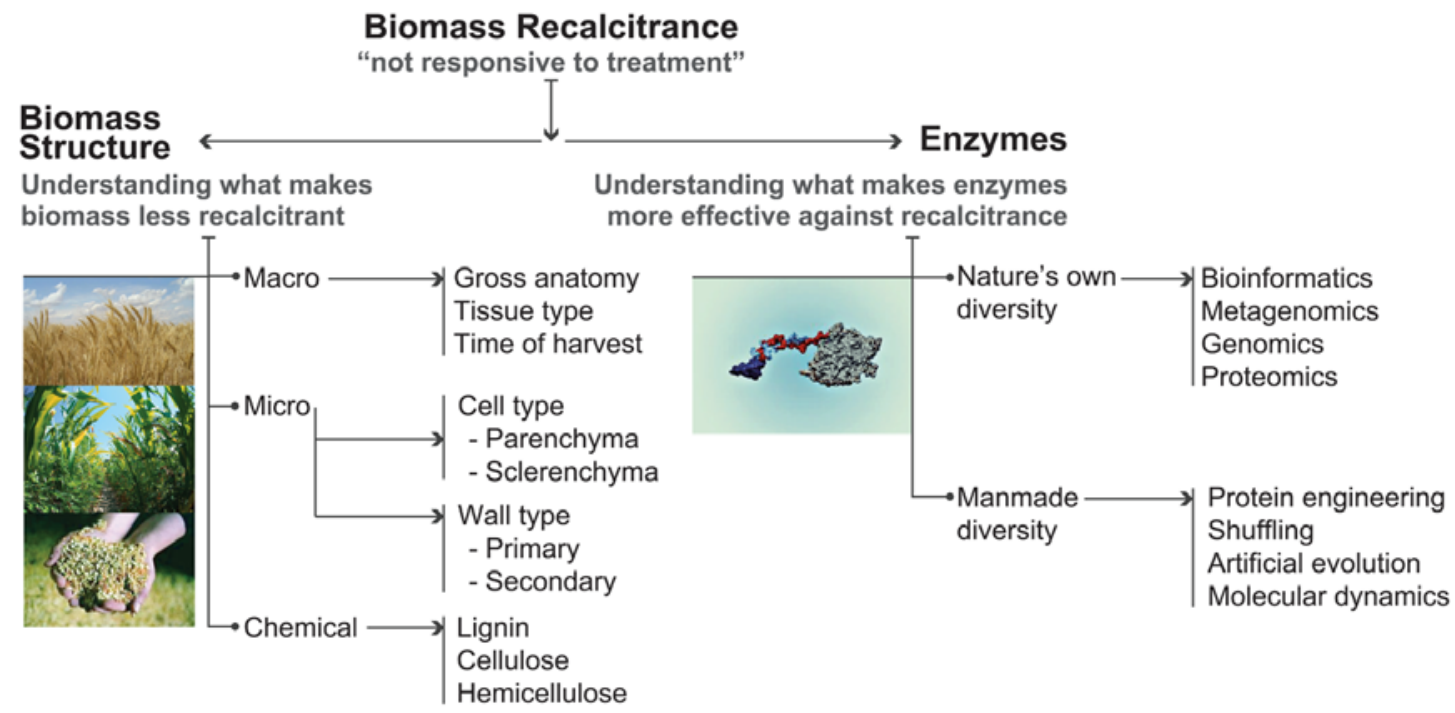

Biomass Recalcitrance

Biomass

Understanding what makes

biomass less recalcitrant
Understanding what makes enzymes more effective against recalcitrance

\section{Research Highlights}
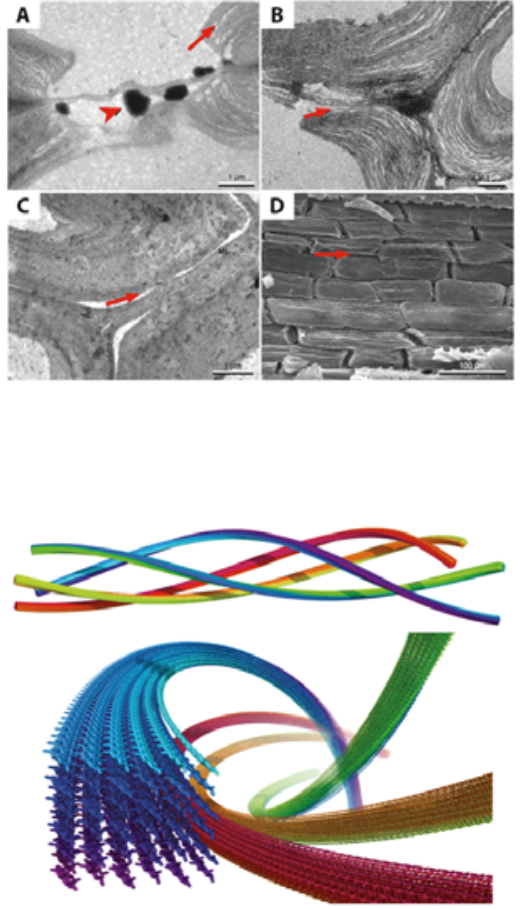

Pretreatment of switchgrass changes cell wall architecture to improve digestibility. Micrographs showing the impact of thermochemical pretreatment on delaminating cell walls and increasing porosity. (A) Pretreatment delaminated secondary cell wall, particularly near cell pits (arrow). (B) Extensive delamination throughout the cell walls (arrow). (C, D) Pretreatment separated adjacent cells by disrupting and dissolving the middle lamella (arrows).

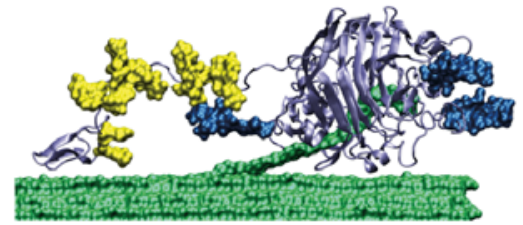

Atomistic, macromolecular models of cellulose microfibrils. The macromolecular geometries extracted from the tomographic data were used to generate atomistic models for cellulose microfibrils based on the $1 \beta$ crystal structure polymorph. The twist of the fibrils was inferred from the macromolecular geometry by orienting the structures such that the bending about the 010 plane of the crystal structure was minimized.

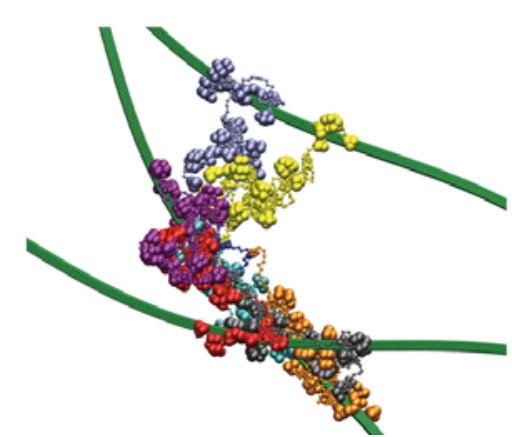

The 0 -glycosylated linker from the Trichoderma reesei Family 7 cellulase is a flexible, disordered protein. Cel7A from Trichoderma reesei on cellulose. The enzyme is shown in purple, the O-glycosylation on the linker is in yellow, and the Nglycan on the $C D$ is in blue. Cellulose is in green, with a single cellodextrin chain threaded into the $C D$ tunnel.

Modeling the self-assembly of the cellulosome enzyme complex. Simulation of a large cellulosome acting on several cellulose microfibrils (green). In cellulosomes, cellulases are arranged on a protein scaffold as opposed to fungal cellulases that are free enzymes. 


\section{OAREL}

\section{Photobiology}

NREL's Photobiology focuses on understanding the capture of solar energy in photosynthetic systems and its use in converting carbon dioxide and water directly into hydrogen and advanced biofuels.

\section{Capabilities}

- Metabolic pathway engineering in algae/ bacteria/cyanobacteria

- Advanced photobioreactors

- Large-scale protein production for characterization of enzymes

- Structure/function relationship in metalloenzymes that catalyze $\mathrm{H}_{2}$ production using biophysical tools such as infrared spectroscopy

- Continuous fermentation for biofuels production
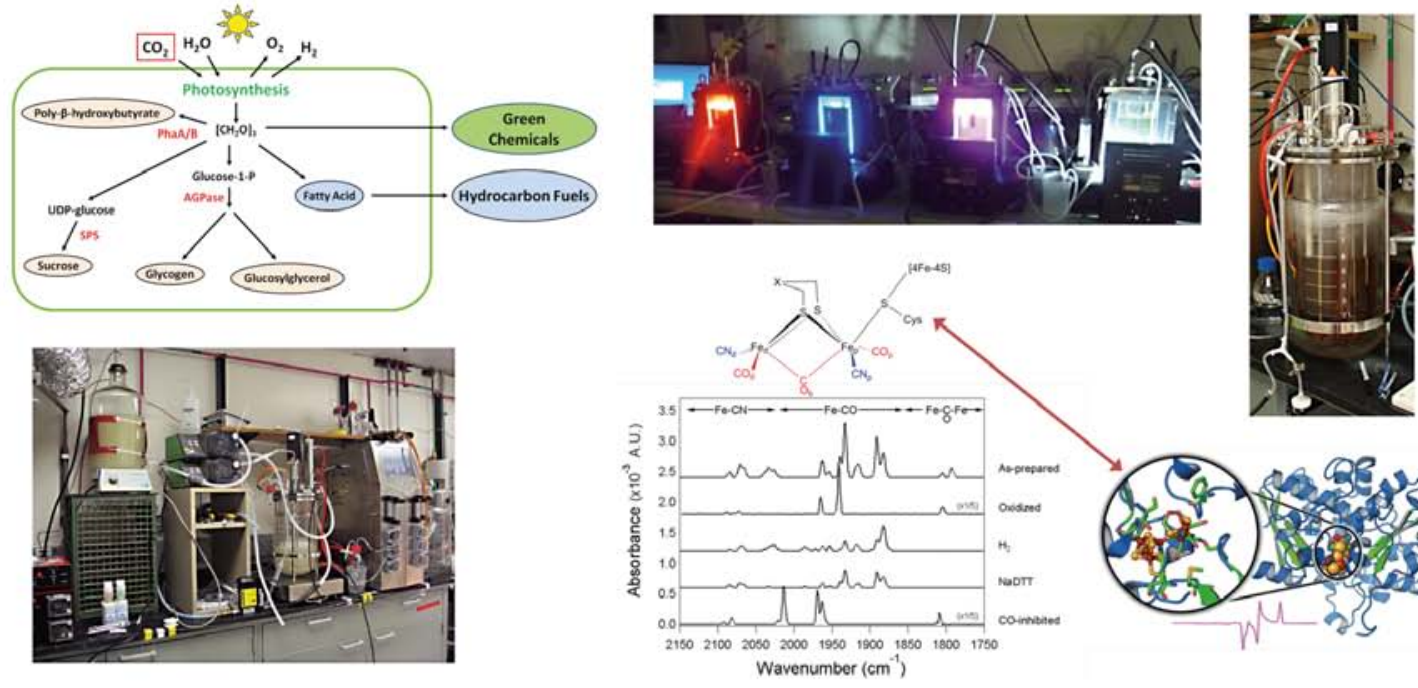

\section{Research Highlights}

Visualization of biofuelsproducing algal cells with colorimetric sensors

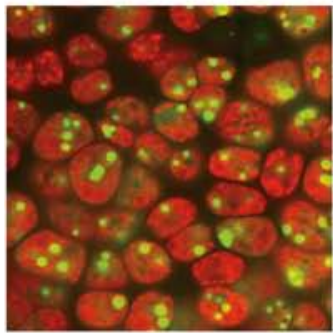

Algal cells (red) stained with a green dye (BODIPY) identifying accumulation of lipids (a valuable fuel precursor)

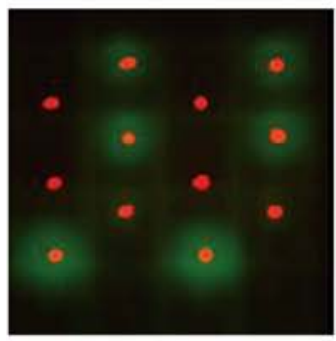

$\mathrm{H}_{2}$ and non- $\mathrm{H}_{2}$ producing algae (red) identified with a biological $\mathrm{H}_{2}$ sensor (green)
Fundamental studies of energy flow from photosynthesis to important biochemical reactions including hydrogen production

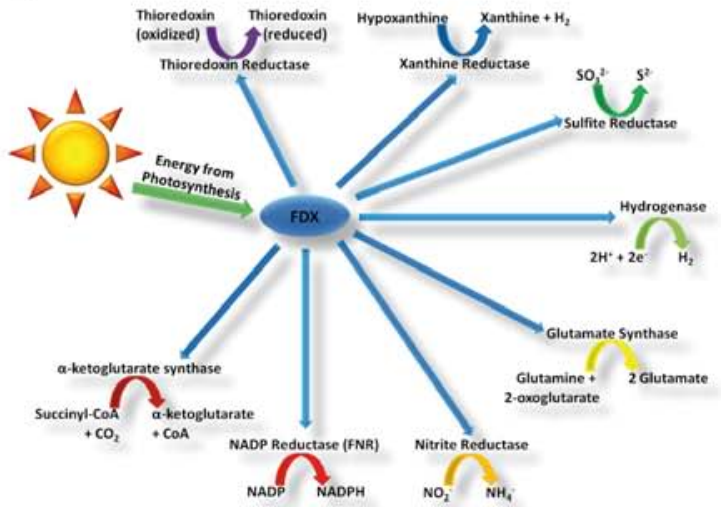

Replacement of algal hydrogenases with a bacterial hydrogenase for increased oxygen tolerance

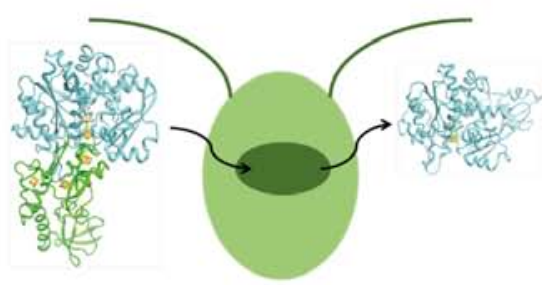

Uptake and utilization of renewable $\mathrm{H}_{2}$ and carbon dioxide $\left(\mathrm{CO}_{2}\right)$ in a novel, engineered micro-organism that directly produces a variety of fuel substitutes

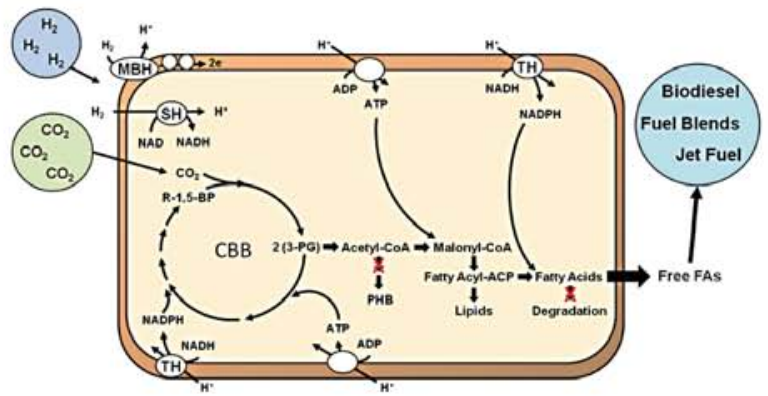

Solar-driven hydrogen production via artificial photosynthesis

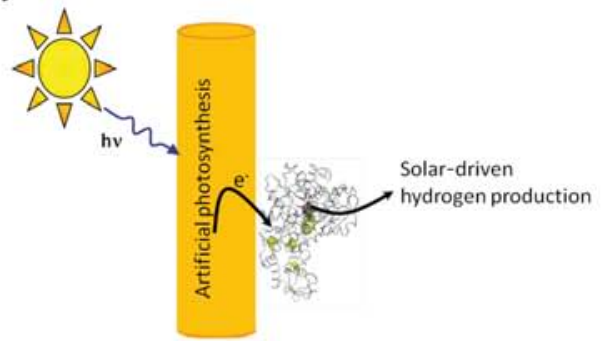

